\title{
Cause Analysis on Pragmatic Failure in Intercultural Communication
}

\author{
Jie Chen \\ College of Foreign Languages, Bohai University, Jinzhou, 121013, China \\ carnation2009@163.com
}

Keywords: intercultural communication; pragmatic failure; cause analysis; English teaching

\begin{abstract}
There are many pragmatic failures in intercultural communication, the analysis of the causes of pragmatic failure is beneficial to reduce the pragmatic failure of intercultural communication and promote the smooth progress of intercultural communication. Based on the domestic and foreign research literature, this paper summarizes the causes of pragmatic failure in intercultural communication as six aspects: "cultural background differences, differences in values differences in ways of thinking, differences in folk custom, negative transfer of mother tongue, the lack of common knowledge, and makes in-depth analysis on these aspects of cause background, manifestations, consequences and points out the effective way to reduce pragmatic failure. Pragmatic failure is an important factor that affects the intercultural communication, the research results of this paper have great significance for promoting intercultural communication and improving the level of English teaching.
\end{abstract}

\section{Introduction}

Communication refers to the process of mutual contacts and exchanging information between people, which is a continuous process of interaction between multiple constituent elements. Communication is not carried out in a vacuum, and always in a certain social and cultural environment. Therefore, communication process and various constituent elements will continuously be influenced by the environment and other factors. When cultural differences in various constituent elements, that is intercultural communication. "Intercultural communication" refers to the communication between native speakers and non-native speakers, it also refers to the communication between the people who have differences in language and cultural background. Pragmatic failure in intercultural communication is caused by cultural differences, pragmatic failure phenomenon is reflected in many aspects. Specifically speaking, speakers do not look at the object, disregard the situation, status, identity of both communication sides, or unconsciously violate social conventions or norms of communication, and the concept of language specific culture value. which leads to communication interruption or failure, encounters obstacles in the process of language communication, finally leads that communication can not achieve desired effects or reach perfect communicative effects [1]. Pragmatic failure has become an important research field of pragmatics and applied linguistics. In order to communicate better in intercultural communication, it is essential to find out the causes of pragmatic failure, and adopt corresponding solutions for the reasons.

\section{Cultural Background Difference}

Because of the different backgrounds of intercultural communication, mistaking usage habits and the way of speaking of own language into the dialogue of two sides, which leads to the failure of communication. People in different cultural background have a habit of self-forming saying. In intercultural communication activities, people are always accustomed to use their own speaking ways to explain others' words, It is natural that take the usage habits of their own language into the intercultural context, which produces pragmatic failures, and leads the communication barriers that both sides can not understand correctly. Because both sides are under the long-term influence of many factors such as different societies, histories, cultures, humanities and geography, the two sides have different value standards, thinking modes and ceremonial expression. Western society pays 
great attention to the individual values, individual ethics become the basic guiding ideology, in contrast, Chinese traditional social values is the tolerant and charity ethics moral. The people who have English culture backgrounds pursue freedom and differences, scrupulous in separating public from private interests, frank and direct, and the people who have Chinese culture backgrounds are often humble, subtle, maintain a good relationship, pursuit harmonious coexistence. The etiquette gap between eastern and western is even greater, such as the expression of polite languages. Most people who have English culture backgrounds are generous to praise others, when the people who have English culture backgrounds receive recognition or praise, they often say "thank you" to accept others' praise. The people who have Chinese culture backgrounds often express politeness with modesty and the truth of denying others praise [2]. For instance, when receive others' praise or compliments, the people who have Chinese culture backgrounds often use courtesy phrases of self-dispraised forms such as "nothing" and "ashamed" and others, through self humility express politeness and gratitude to others. In ancient China, it is a kind of taboo that women look straight at men, however, when British and American chat, they also try to look into each other's eyes, this is a kind of polite expression, in order to let them know I'm listening. In modern society, when communicating with others we also need to look into the eyes of the other side, which shows the shape of a triangle.

\section{Values Difference}

Values refer to systematic views and viewpoints of the value phenomenon or value relation formed in people's mind. The cultural environment of each person's life is different, the values are also different. Values are the core of a national culture, in order to correctly understand the language and behavior of a nation, we must thoroughly understand the core values of the nation. The differences of Chinese and Western cultural values mainly represent in the following three aspects:

(1) Opposition of the relationship between individual values and group values. The west is individualism culture values, self-centered, individual-oriented, which in intercultural communication shows strong affirmations and highlights self-color. It advocates individual values are the highest, individual values are higher than group values, individual values are the source of group values. China is collectivism culture values, which advocates collective values are higher than individual values, the individual as a member of society, emphasizes the individual's responsibility to society and other people, the mutual help and concern between people.

(2) Opposition of the relationship between life values and moral values. The west advocates life values are higher than everything, moral values are subject and belong to life values. It emphasizes individual interests are the only realistic interest and as a standard of measuring good and evil. The behavior which contributes to achieving personal interests and obtaining personal happiness is all moral, moral is the condition and means of achieving personal interests and obtaining personal happiness. Chinese traditional cultures attach attention to moral values, moral values are higher than everything, which sums up life values as moral values. It improve the individual's moral education to the absolute position, which judge life by morality.

(3) Opposition of the relationship between utilitarian values and ethical values. Western values show a strong utilitarian color, which emphasize individual interests are the only realistic interest, and take individual interests as a standard to measure good and evil, utilitarian principle is the starting point of social life and the highest principles of morality. Chinese traditional culture values pay more attention to loyalty over money, which take affection as the main line, family human relationships as the center, ethical values in interpersonal empathy as the starting point. The ethical values of Chinese traditional culture are full of strong emotional colors, humanized tendency is very outstanding, which emphasize to establish moral values of pursuing morality and justice.

\section{Thinking Mode Difference}

Thinking activity is a dynamic system composed of many factors, thinking object, thinking subject and thinking mode are the three main factors in the thinking activities. Thinking object is the raw 
material of thinking activity; Thinking subject is the person who has the cognitive ability and thinking structure; Thinking mode is the method, tool and means for thinking subject makes process on thinking object. In thinking activity, thinking mode plays an important role, which forms the intermediary and bridge that thinking subject and thinking object make contact. Thinking mode is ultimately the reflection of the relationship and the law between objective things. The development of thinking mode is restricted by the objective conditions such as the scale and level of social practice, the development degree of practical ways, and develops along with the history practice. Culture influences the views people look at the outside world, different countries have different cultures, so there must be different in thinking mode, this point especially performances significantly between oriental and western culture. Thinking mode of western culture pays attention on logic and analysis, thinking mode of oriental culture shows intuition integrity, this is also the characteristics of Chinese traditional culture thinking. In essence, thinking tendency frequently ignores the difference between individual things, which exaggerates the cognitive attitude associated with a certain social group, along with the emotional color, and accompanied with fixed creed. In all of the sets, some sets are correct, but some are wrong, which directly affect the intercultural communication, lead to the communication faults [3].

\section{Folk Customs Difference}

Folk customs are a way of life that a country or a nation gradually forms, repeatedly appears, learns from generation to generation in the long-term historical development process, which is a kind of social norm, reflected in many aspects such as the clothing, food, shelter, transportation, production, trade, folk beliefs, weddings and funerals, at the age of festivals. Folk customs vividly reflects the characteristics of a nation's living habits, behavior, ethics and so on, it is the main content which constitutes the culture of national life [4]. Folk customs are not produced without foundation, a nation's politics, economy, religion, psychology, language and other factors that determine and influence the folk customs. Any folk customs are not individual behavior, but convent by all members within the nation in common social life and universally heritage by society. Once the folk customs are produced, it is bound to the thought and behavior of the members of national society, especially with the folk customs with faith, which is greater bound. In real life, people in front of folk customs have a kind of consistency who agree without precious consultation. Folk customs are an important supplement to the law, sometimes it can play the role that the law can not. Folk customs of all nations have the specific performance of content and requirements, the difference between nations is very big, each nation has a special emotion on the national folk customs, some are proud, some make it in divine, not only abide by their own tenets, and not violated by outsiders. Therefore, in intercultural communication, communicative failure often occurs because people do not understand folk customs with each other, which even bring great conflict. Taboo is also an important content of folk custom, which is the most sensitive issue in intercultural communication and also the most important aspect that should be paid attention to in intercultural communication.

\section{Negative Transfer of Mother Tongue}

According to the theory of "mother tongue transfer", in the process of second language acquisition, learners' first language, the usage habits of mother tongue will directly affect the acquisition of second language, and it plays a positive promoting or negative interference role. According to the principle of education psychology, it is called positive transfer that mother tongue makes beneficial and positive effects for foreign language acquisition because of the similar ingredients with foreign language, which can promote learners' mastery for foreign language; On the contrary, it is called negative transfer that mother tongue makes unfavorable and negative effects for foreign language acquisition because of the different ingredients with foreign language, which is an obstacle to master a foreign language for learners. In the acquisition process, positive and negative transfer exist simultaneously and have an effect on foreign language acquisition at the same time. Language is the carrier of culture, any language contains rich culture. Learners always tend to use their own 
cultural standards to measure others' words and deeds and thoughts, with their own habits of mother tongue to express their own thoughts, apply mechanically the pragmatic meaning of mother tongue for a word or a certain structure, which ignores the cultural connotations contained in the second language, so that communicative failures occur frequently.

In the process of using target language to communicate, in order to achieve the purpose of communication, the pragmatic rules and linguistic rules of target language must be mastered. Pragmatic rules are the pragmatic knowledge that understand and implement all kinds of speech acts, which implicit the thinking mode and the deep culture of the language ethnic; Language rules are grammar suitability, which mean arrangements such as word, phrase, sentence and chapter are in accordance with the internal mechanisms of the language. In the process of communication, the first thing is to have a communicative intention, if convey the intention in single language rules and pragmatic rules, it is easy to achieve the purpose of transmitting information correctly. However, in the process of foreign language learning, when there is a communicative intention, using pragmatic rules of target language will be tried, because too little knowledge in this aspect, which will naturally turn to the pragmatic rules of mother tongue or the intermediate language rules which is influenced by the mother tongue, so that the communicative intention is changed when the other party accepts. Similarly, when receiving information, similar cases also happen, failure to understand the conveyed information of target language according to the pragmatic rules of target language, however, when using the pragmatic rules of their own mother tongue to understand, also will misunderstand each other, resulting in pragmatic failure. The two processes are shown in Fig.1.

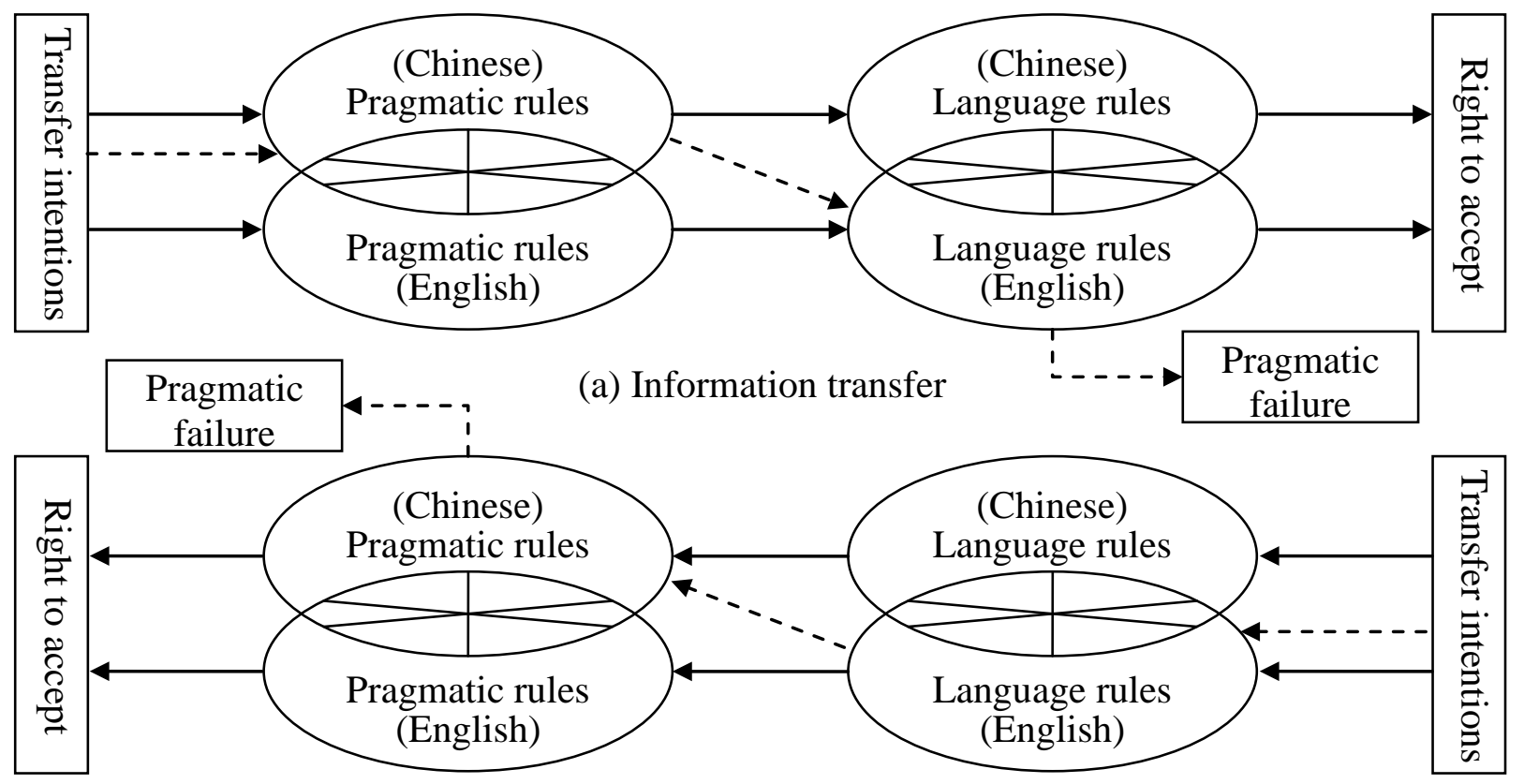

(b) Information received

Fig. 1. Process on information transfer and information received

Fig. 1 indicates respectively the situation of information transmission and information acceptance. In the process of transmission and acceptance, if obey the linguistic and pragmatic rules in the same language, information transmission and reception are open right (solid line in the picture); on the contrary, if the pragmatic rules complied change, which means that if using Chinese pragmatic rules in the two process, migrating Chinese pragmatic rules into the process of information transmission and interpretation, pragmatic failure occurs. 


\section{Common Knowledge Lack}

Common knowledge lack includes language knowledge lack and social culture knowledge lack. Language is the carrier of culture, because different nationalities and countries have different natural environment and social environment, life style and values, so that the deep cultural accumulation of all nationalities thinking clearly reflects in language. When students do not quite understand of the target language, it is easy to migrate corresponding words simply from the native language to the target language, which makes the fault, or use the vocabulary when know very little about the implication of the target language vocabulary. For example, students only know interrogative sentences express doubt, and do not know interrogative form is sometimes used to express modesty, politeness and negative meanings, so often regard the sentences with interrogative words as interrogative sentences to answer; each language has its cultural foundations, the attitude of all kinds of cultures for the same thing may be different. The way that different cultural atmosphere communicators understand and comply with what is the proper speech act is different. In China, traditional culture pays high attention to family blood relationship, which performances in daily life that greets between family members to show concern. Cultural accumulation for long time, the non relative person greets as well as the family when meet with each other, and often takes in conversation others life as a topic, in order to express the cordial relationship between each other. This is the reason why the Chinese often take the private problem as the topic when meet with each other. If you do not know these cultural factors, in communication will cause pragmatic failure.

\section{Conclusion}

Good interpersonal communication skills and interpersonal relationship are a necessary condition for survival and development. Intercultural communication is a kind of communicative behavior, which can be the interpersonal communication, and it can also be the communication between individuals and groups [5]. Economic globalization and information network, which make globalization become an irreversible trend, people from different regions and cultural backgrounds form a survival position in the world citizen identity, intercultural communication ability becomes the basic survival skills of people [6]. There are many pragmatic failures in intercultural communication. The analysis of the causes of pragmatic failure is benefit to reduce the pragmatic failure of intercultural communication and promote the smooth progress of intercultural communication. Through the analysis of the various kinds of performances of pragmatic failures, it can be seen that there are many deep level reasons such as history, culture and value concept behind intercultural communication. A great deal of understanding and absorbing foreign cultures, strengthening the contrast between different cultures is an effective way to reduce the pragmatic failures in intercultural communication.

\section{References}

[1] Manuel Padilla Cruz, "Pragmatic failure, epistemic injustice and epistemic vigilance," Language \& Communication, vol. 39, no. 1, pp. 34-50, 2014.

[2] L. Wu, "Pragmatic failure and preventive strategies in cross cultural communication," Educational theory and Practice, vol. 34, no. 24, pp. 46-47, 2014.

[3] J.D. DeFreese, Alan L. Smith, "Teammate social support, burnout, and self-determined motivation in collegiate athletes," Psychology of Sport and Exercise, vol. 14, no. 2, pp. 258-265, 2014.

[4] F. Zhao, "Study on the cultivation mode of 'penetrating' Intercultural Communication Competence," Doctor's degree of Shanghai International Studies University, 2014. 
[5] L. Gao, F. Wang, "A tentative approach to intercultural communicative competence," Journal of Northwest University (Philosophy and Social Sciences Edition), vol. 37, no. 3, pp. 116-119, 2007.

[6] X. Y. Wang, "Cross cultural communication and training of College Students' intercultural communicative competence," Journal of Hehai University (Philosophy and Social Sciences), vol. 13, no. 1, pp. 85-88, 2011. 